\title{
PENGARUH KURVA HISTERESIS TERHADAP MODEL STABILITAS LERENG TIMBUNAN AKIBAT KEGIATAN PERTAMBANGAN DI ZONA LAHAN BASAH
}

\author{
The influence of hysteresis curve on the stability model of disposal slope \\ due to mining activities in wetland zone \\ Reza Adhi Fajar ${ }^{*}$, Lilik Eko Widodo ${ }^{2}$, Gunawan Handayani ${ }^{3}$, Tedy Agung Cahyadi ${ }^{1}$ \\ ${ }_{1}^{1}$ Program Doktor Rekayasa Pertambangan ITB, Ganesa 10, Bandung, Indonesia \\ 2 Staf Pengajar dan Grup Riset Eksplorasi Sumberdaya Bumi ITB, Ganesa 10, Bandung, Indonesia \\ ${ }^{3}$ Staf Pengajar dan Grup Riset Fisika Bumi ITB, Ganesa 10, Bandung, Indonesia \\ *Corresponding author: reza@poliban.ac.id
}

\begin{abstract}
Landfill of residual soil due to mining activity in the wetland area is a relatively complex issue due to the soft soil conditions that are vulnerable to landslides. The stabilization method to increase the safety factor from landslide hazard can be done by decreasing the degree of water saturation in the soil disposal. In this case, the dominant mechanical parameters used in slope stability analysis will be elaborated with the SWCC concept for soft soil. While the conceptual model is built, it is based on the phenomenon of negative pore water pressure that appears in the vadose zone on the groundwater surface. The information provided from the hysteresis curve configuration can be used as an additional reference for the optimistic disaster analysis.
\end{abstract}

Keyword: hysteresis, stability, disposal, soil, saturation.

\section{PENDAHULUAN}

Karakteristik media tanah tak jenuh dalam siklus infiltrasi dan evaporasi, akan membentuk hubungan hysteresis yang juga disebut sebagai soil water charachteristic curve (SWCC). Umumnya, SWCC diperoleh dari pengujian laboratorium untuk mendapatkan hubungan antara tekanan air negatif (suction) terhadap kadar air atau derajat kejenuhan pada sampel tertentu. Namun demikian, ia juga sebenarnya juga merupakan representasi dari kondisi lapangan yang ditunjukkan sebagai hubungan antara matric suction, selisih tekanan udara dan air, terhadap parameter kekuatan tanah tak jenuh (Fredlund dan Rahardjo, 1993)

$\mathrm{Di}$ sisi lain, galian tanah akibat kegiatan pertambangan di daerah lahan basah seringkali menimbulkan persoalan kemantapan lereng terlebih bilamana di daerah yang berdekatan dengan pemukiman. Analisa kemantapan lereng yang dipergunakan dalam menghitung probabilitas kebencanaan cenderung pada asumsi pesimistik dimana tanah residu tersebut dianggap dalam kondisi jenuh air sehingga kemiringan timbunan menjadi sangat landai. Tulisan ini mengeksplorasi pengaruh variasi tekanan negatif pori air guna analisis kebencanaan yang bersifat optimitik.

\section{METODE}

Pendekatan yang dilakukan mengacu pada pengetahuan tentang mekanika tanah tak jenuh dengan memperhitungkan kontribusi kuat geser tambahan di atas muka air dalam timbunan. Gambar 1 mengilustrasikan bahwa genangan air tidak merata pada timbunan tanah sehingga terjadi pengurangan tegangan total di sebagian zona dekat permukaan.

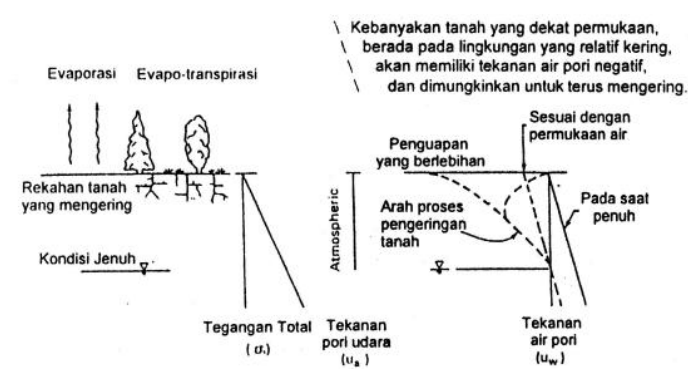

Gambar 1. Distribusi Tegangan di atas Muka Airtanah (Fredlund \& Rahardjo 1993)

Sehingga kriteria keruntuhan Mohr-Coulomb juga harus disesuaikan dengan konsep tak jenuh sebagaimana ditunjukkan pada gambar 2, dengan persamaan kuat geser sebagai berikut (Fredlund \& Rahardjo 1993):

$$
\tau_{f f}=c^{\prime}+\left(\sigma_{n f}-u_{a}\right) \tan \phi^{\prime}+\left(u_{a}-u_{w}\right)_{f} \tan \phi^{b}
$$


dengan $\tau_{f f}, u_{a f}, \phi^{b}\left(\sigma_{f}-u_{a}\right)$ adalah, kuat geser tanah tak jenuh, tekanan air pori tanah di bidang runtuh pada saat failure, sudut kuat geser efektif terhadap matric suction, dan variabel tegangan normal di bidang runtuh saat failure. Sedangkan kohesi:

$$
c=c^{\prime}+\left(u_{a}-u_{w}\right)_{f} \tan \phi^{b}
$$

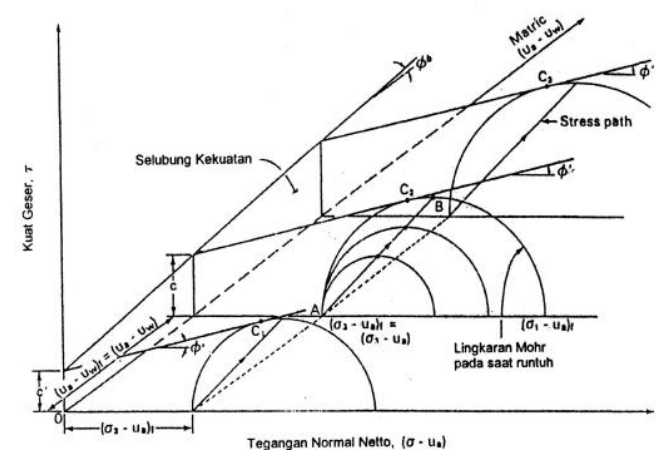

Gambar 2. Diagram Selubung Kekuatan MohrCoulomb untuk media tak jenuh (Fredlund dan Rahardjo, 1993)

Namun demikian, dalam perhitungan kelongsoran lereng tanah tersebut, tetap mengikuti konsep piasan (Bishop \& Blight 1963) dengan penambahan beberapa variabel baru (gambar 3), yakni:

- Persamaan kuat geser

$S_{m}=\beta / F\left\{c^{\prime}+\left(\sigma_{f}-u_{a}\right) \tan \phi^{\prime}+\left(u_{a}-u_{w}\right)_{f} \tan \phi^{b}\right\}$

- Persamaan gaya normal

$$
\begin{aligned}
& W-\left(X_{R}-X_{L}\right)-S_{m} \sin \alpha-N \cos \alpha=0 \\
& N=\frac{W-\left(X_{R}-X_{L}\right)-\frac{c^{\prime} \beta \sin \alpha}{F}+u_{\alpha} \beta \sin \alpha\left(\tan \phi-\tan \phi^{b}\right)+u_{w} \frac{\beta \sin \alpha}{F} \tan \phi^{b}}{F} \\
& \cos \alpha+\frac{\sin \alpha \tan \phi^{\prime}}{F}
\end{aligned}
$$

- Persamaan FK untuk Momen

$$
A_{L} a_{L}+\sum(W \cdot x)-\sum(B . f)-\sum\left(S_{m} \cdot R\right)=0
$$

$F_{m}=\frac{\sum\left[c^{\prime} \beta R+\left\{N-u_{w} \beta \frac{\tan \phi^{b}}{\tan \phi}-u_{a} \beta\left(1-\frac{\tan \phi^{b}}{\tan \phi}\right)\right\} \cdot R \tan \phi\right]}{A_{L} a_{L}+\sum(W . x)-\sum(N . f)}$

- Persamaan FK untuk Gaya

$-A_{L}+\sum\left(S_{m} \cos \alpha\right)-\sum(N \sin \alpha)=0$

$F_{f}=\frac{\sum\left[c^{\prime} \beta R+\left\{N-u_{w} \beta \frac{\tan \phi^{b}}{\tan \phi}-u_{a} \beta\left(1-\frac{\tan \phi^{b}}{\tan \phi}\right)\right\} \tan \phi^{\prime} \cos \alpha\right]}{A_{L}+\sum(N \sin \alpha)}$

dengan fungsi gaya antar pias dari hubungan

$$
\begin{aligned}
& \left(E_{R}-E_{L}\right)=N \cos \alpha \tan \alpha-S_{m} \cos \alpha, \text { dan } \\
& X=\lambda \cdot f(x) E \text { dengan } f(x)=K \cdot e^{-\left(C^{n} \omega^{n}\right) / 2} \text { dan }
\end{aligned}
$$

$K=. \exp \left\{D_{i}-D_{s}\left(D_{f}-1.0\right)\right\}$

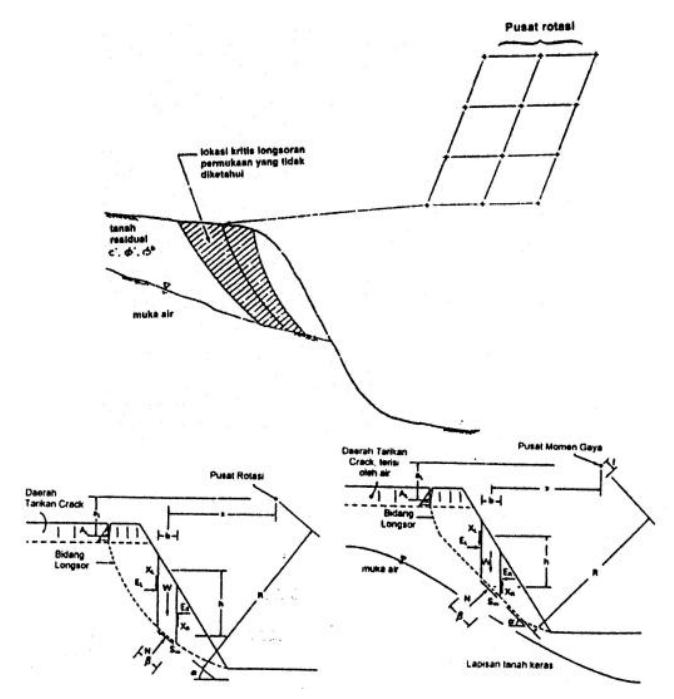

Gambar 3. Modifikasi Komponen Gaya Dalam Metoda Bishop (Fajar dkk, 2001)

\section{HASIL DAN PEMBAHASAN}

\subsection{Parameterisasi}

Untuk keperluan simulasi, kemiringan awal lereng timbunan diasumsikan dalam kondisi jenuh air (di seluruh titik) sehingga dimensinya menjadi sangat landai.

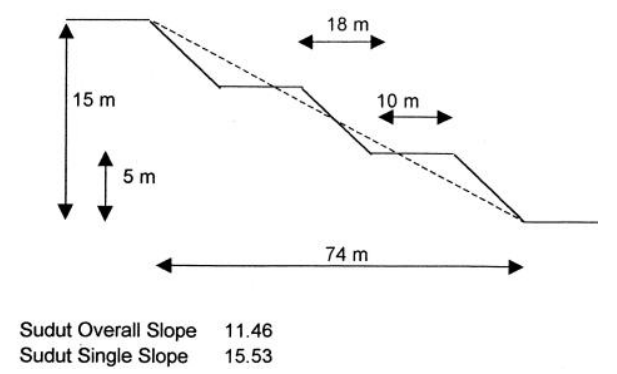

Gambar 4. Kemiringan Lereng Timbunan (simulasi)

Sedangkan model tanah residu (soft over burden) yang disimulasikan adalah lempung dengan kepadatan yang relatif rendah dengan parameter fisik sebagaimana ditunjukkan pada tabel 1. Hal ini bersesuaian dengan kurva hubungan hysteresis parameter kuat geser tanah tak jenuh untuk kondisi tanah yang serupa (gambar 5). Di lain pihak, parameter mekanik yang diambil merupakan komposisi dari pengujian direct shear dan triaxial (tabel 2). Parameter $\phi^{b}$ diprediksi setara dengan 95\% dari nilai parameter $\phi$ (Chiu dkk 2012, Song 2014) 
Tabel 1. Parameter Fisik Tanah Timbunan

\begin{tabular}{ccc}
\hline Column 1 & Satuan & Nilai \\
\hline Kandungan Air Tanah & $\%$ & 15,79 \\
Berat Jenis & - & 2,54 \\
Berat Isi Basah & $\mathrm{kN} / \mathrm{m}^{3}$ & 17,25 \\
Berat Isi Kering & $\mathrm{kN} / \mathrm{m}^{3}$ & 14,90 \\
Angka Pori & - & 0,67 \\
Porositas & $\%$ & 40,20 \\
Derajat Kejenuhan & $\%$ & 59,66 \\
\hline
\end{tabular}

Sumber: Laboratorium Mekanika Tanah (lempung densitas rendah)

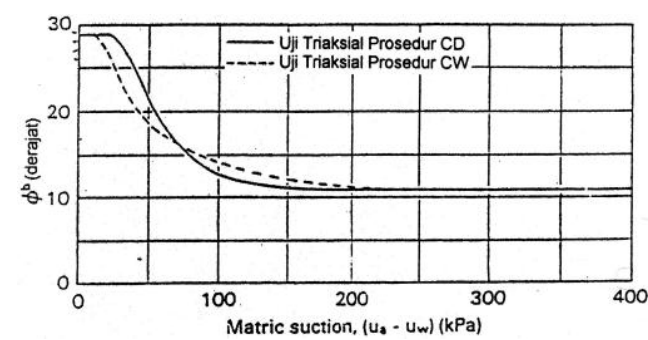

Gambar 5. Hubungan non-linier parameter $\phi^{b}$ dan matric suction untuk tanah lempung dengan kerapatan rendah (Oh \& Lu 2015)

\section{3 Simulasi Model}

Perhitungan dilakukan dengan memanfaatkan aplikasi macro dalam perangkat lunak spreadsheet (MS.Excel) dengan konvergensi yang relatif stabil setelah iterasi ke-7 (gambar 6). Input parameter dibuat bervariasi terhadap tekanan air pori negatif menurut 4 (empat) jenis hasil uji sifat mekanik, masing-masing dalam prosedur unconsolidated undrained (UU), consolidated undrained (CU) dan consolidated drained (CD). Angka faktor keamanan ditetapkan sama atau lebih dari 1,25.

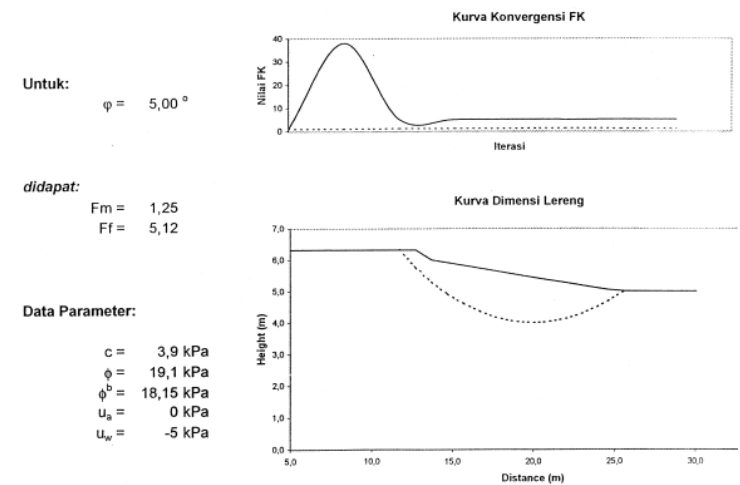

Gambar 6. Contoh Perhitungan (macro-excel)

Rekapitulasi perhitungan ditunjukkan pada tabel 2 berikut ini:
Tabel 2. Hasil Analisis Kemantapan Lereng Timbunan

\begin{tabular}{|c|c|c|c|c|c|c|c|}
\hline \multirow{2}{*}{$\begin{array}{l}\text { Metoda \& } \\
\text { Kondisi }\end{array}$} & \multicolumn{3}{|c|}{ Parameter acuan } & \multirow{2}{*}{$\begin{array}{c}-\mathrm{U}_{\mathrm{w}} \\
(\mathrm{kPa})\end{array}$} & \multirow{2}{*}{$\begin{array}{l}\text { Sudut } \\
\text { Lereng } \\
\text { (o) }\end{array}$} & \multicolumn{2}{|c|}{$\begin{array}{c}\text { Faktor } \\
\text { Keamanan }\end{array}$} \\
\hline & $\begin{array}{c}\mathrm{C} \\
(\mathrm{kPa})\end{array}$ & $\phi\left({ }^{\circ}\right)$ & $\phi^{\mathrm{b}}\left({ }^{\circ}\right)$ & & & $\mathrm{Fm}$ & $\mathrm{Fk}$ \\
\hline \multicolumn{8}{|l|}{ Triaxial - UU: } \\
\hline Jenuh & 4,9 & 8,1 & - & 10 & 6,2 & 1,25 & 3,58 \\
\hline \multicolumn{8}{|l|}{ Direct Shear: } \\
\hline Jenuh & 4,7 & 18,4 & 17,48 & 0 & 7,2 & 1,25 & 5,63 \\
\hline Tak Jenuh & 4,7 & 18,4 & 17,48 & -5 & 7,6 & 1,25 & 5,62 \\
\hline Tak Jenuh & 4,7 & 18,4 & 17,48 & -10 & 8,1 & 1,25 & 5,57 \\
\hline Tak Jenuh & 4,7 & 18,4 & 17,48 & -20 & 9,0 & 1,25 & 5,46 \\
\hline \multicolumn{8}{|l|}{ Triaxial - CU: } \\
\hline Jenuh & 4,4 & 14,2 & 13,49 & 0 & 5,8 & 1,25 & 6,49 \\
\hline Tak Jenuh & 4,4 & 14,2 & 13,49 & -5 & 6,1 & 1,25 & 6,46 \\
\hline Tak Jenuh & 4,4 & 14,2 & 13,49 & -10 & 6,4 & 1,25 & 6,42 \\
\hline Tak Jenuh & 4,4 & 14,2 & 13,49 & -20 & 7,0 & 1,25 & 6,33 \\
\hline \multicolumn{8}{|l|}{ Triaxial - CD: } \\
\hline Jenuh & 3,9 & 19,1 & 18,15 & 0 & 4,3 & 1,25 & 5,05 \\
\hline Tak Jenuh & 3,9 & 19,1 & 18,15 & -5 & 5,0 & 1,25 & 5,12 \\
\hline Tak Jenuh & 3.9 & 19.1 & 18.15 & -10 & 5.5 & 1.25 & 5,17 \\
\hline Tak Jenuh & 3.9 & 19.1 & 18.15 & -20 & 66 & 1.25 & 5,18 \\
\hline
\end{tabular}

Kompilasi ini mengambarkan bahwa besar penerjalan sudut pada lereng timbunan dapat ditingkatkan hingga $10 \%$.

\section{SIMPULAN}

Pengaruh variasi tekanan negatif pori air pada tanah timbunan hasil aktivitas pertambangan di daerah lahan basah, telah disimulasikan. Kurva hysteresis atau SWCC disini, digambarkan sebagai kurva hubungan parameter kuat tanah tak jenuh terhadap variasi matric suction. Sentuhan analisis sensitivitas yang diterapkan dalam konteks bahaya longsor (kebencanaan) di daerah lahan basah ini, bersifat optimitik,

\section{UCAPAN TERIMA KASIH}

Terima kasih atas bantuan pendanaan LP3I-ITB sehingga tulisan ini dapat dipublikasikan.

\section{DAFTAR PUSTAKA}

Bishop, A.W \& Blight, G.E (1963) Some Aspects of Effective Stress in Saturated and Unsaturated Soils. Journal of Geotechnics. 13:177-197

Chiu, C.F., Yan, W.M., Yuen, K-V (2012) Reliability analysis of soil-water characteristics curve and its application to slope stability analysis. Journal of Engineering Geology 135-136:83-91

Fajar, R.A (2001). Penentuan Parameter Kekuatan Tanah Tak Jenuh Untuk Analisis Kemantapan Lereng (unpublished thesis). Bandung: Institut Teknologi Bandung. 
Fredlund, D.G \& Rahardjo, H. (1993). Soil Mechanics For Unsaturated Soils. Toronto: A WileyInterscience Publication: John Wiley \& Sons, Inc.

Oh, S. \& Lu, N. (2015). Slope stability analysis under unsaturated conditions: Case studies rainfallinduced failure of cut slopes. Journal of Engineering Geology 184:96-103.

Song, Y-S (2014) Suction stress in unsaturated sand at different relative densities. Journal of Engineering Geology 176:1-10 